\title{
In Vitro Remineralization of Acid-etched Bovine Enamel with Amino Acids/Hydroxyapatite Composite
}

\author{
LIU Ji-Tao ${ }^{1,2}$, CHUAN Ding-Ze ${ }^{1}$, YANG Ze-Bin ${ }^{1}$, CHEN Xi-Liang ${ }^{1}$, YAN Ting-Ting ${ }^{1}$, CHEN Qing-Hua ${ }^{1}$ \\ (1. Faculty of Materials Science and Engineering, Kunming University of Science and Technology, Kunming 650093, China; \\ 2. Yunnan Baiyao Group Co., Ltd, Kunming 650500, China)
}

\begin{abstract}
Remineralization of early enamel caries lesions plays a crucial role in prevention and restoration of dental caries. Based on the crucial amino acids contained in enamel matrix, amino acids /hydroxyapatite (AA/HAP) composite was synthesized in the presence of $10 \mathrm{mmol} / \mathrm{L}$ glycine, $10 \mathrm{mmol} / \mathrm{L}$ L-serine and $5 \mathrm{mmol} / \mathrm{L}$ L-aspartic acid. The physical, chemical and biological properties of the composite were characterized. And its remineralization effect on acid-etched bovine enamel was evaluated. Under the inhibition properties of amino acids, the composite has lower crystallinity and higher biocompatibility compared to the hydroxyapatite (HAP) without amino acids. In vitro remineralization of acid-etched bovine enamel using AA/HAP was conducted in artificial saliva. After remineralization, the surface and cross-section morphology, the components, and the mechanical property of bovine enamel samples were characterized, respectively. The results showed that the AA/HAP could induce the restoration of both surface and subsurface enamel lesions. The amino acids released from the composite could adsorb on the organic matrix residues and induce the formation of parallel arranged HAP crystals, eventually formed significant surface microhardness (SMH) recovering.
\end{abstract}

Key words: remineralization; enamel; hydroxyapatite; amino acid

Tooth enamel, the hardest tissue in human body, is composed of around $96 \mathrm{wt} \%$ hydroxyapatite (HAP, $\left.\mathrm{Ca}_{10}\left(\mathrm{PO}_{4}\right)_{6}(\mathrm{OH})_{2}\right), 3 \mathrm{wt} \%$ of water and less than $1 \mathrm{wt} \%$ organic matrix ${ }^{[1-2]}$. Its special properties are ascribed to the structure of parallel arranged HAP prisms (which wrapped in a thin layer of organic matrix $)^{[3-4]}$. This special structure has an abnormal consistency across all species despite the diversity of other tissues. Such invariability suggests that enamel has a common structural and functional basis between different species ${ }^{[3,5]}$.

Unlike synthetic HAP, the HAP in teeth is often calcium deficient due to cations substitutions, which making enamel vulnerable to acid-etching ${ }^{[6-7]}$. Enamel is always exposed to acidic food or drink, as well as the acidic by-products produced by cariogenic bacteria. Therefore, enamel caries has been a major oral health problem worldwide. Fluoride is currently the most effective and widely used anti-caries method. It can reduce enamel demineralization and promote enamel remineralization. A relatively high concentration of fluoride could increase abrasion resistance and decrease caries process in enamel ${ }^{[8]}$. However, excessive exposure to fluoride may induce fluorosis.
In recent years, biomimetic remineralization methods have been paid great attention. For example, amelogenin and its mimetic assembly supramolecular ${ }^{[9-10]}$ was applied in ex vivo remineralization of artificial enamel lesions. Other biomimetic methods, such as amelogeninderived peptides ${ }^{[11]}$ and repeats of aspartate-serine-serine peptides $^{[12]}$ was also clarified to have biomineralization effect on enamel lesions. However, it is very difficult and too expensive to extract or synthesize these natural proteins or peptides, hence limit the application of these methods. Besides, most of the investigations mentioned above are more concerned about enamel surface remineralization. Regeneration of subsurface and deep enamel lesions was rarely referred to.

As the outermost layer of the tooth, enamel is always exposed to a complex oral environment. Therefore, enamel evolved to be more resistant to demineralization than other mineralized tissues ${ }^{[6]}$. Furthermore, enamel has a hierarchical graded structure ${ }^{[13]}$. Its hardness decreases obviously from outer layers to the direction of dentin-enamel junction (DEJ), which is attributed to the less ordered enamel prisms, more crystal defects, lower mineral density and higher organic matrix contents ${ }^{[14]}$. 
Once been etched by acid, the subsurface demineralization will form white spot lesions (WSLs) at first. Without effective treatment, WSLs would turn into caries thereby increasing the application of invasive restorative treatments ${ }^{[15]}$.

As a biocompatible and bioactive material, synthesized HAP has been widely used in remineralization of enamel lesions ${ }^{[16-17]}$. Nonetheless, these methods mainly utilized the size effect of HAP for the formation of mineralized layers in the cavities of the enamel surface. With a similarity in crystallinity to the apatite in bone and enamel, these HAP materials have poor solubility and only can provide limited $\mathrm{Ca}^{2+}$ and $\mathrm{PO}_{4}{ }^{3-}$ ions for enamel remineralization. Therefore, the invasive restorative treatments is still badly in need of new strategy.

Glycine (Gly), L-serine (Ser) and L-aspartic acid (Asp) are the pivotal amino acids contained in the enamel matrix at different stages of amelogenesis ${ }^{[1,18]}$. Molecular dynamic simulations showed that the (002) faces of HAP tend to be unstable in Gly solutions ${ }^{[19]}$. Thus, the ordered assembly of HAP crystals along the $c$-axis was facilitated for minimizing the total interfacial energy. Meanwhile, Gly has the smallest molecular size in amino acids, and it is easy to diffuse into the deep layer of enamel lesions. Ser with hydroxyl side group and Asp with carboxyl side group both have high affinity for $\mathrm{HAP}^{[20]}$. In addition, HAP is proved to be positively charged when orientated along the $c$-axis ${ }^{[21]}$. Therefore, the molecular of Ser and Asp could strongly integrate with the positively charged enamel prisms via electrostatic adsorption, and facilitate the topical supersaturation of $\mathrm{Ca}^{2+}$ and $\mathrm{PO}_{4}{ }^{3-}$ in the subsurface enamel lesions. In the synthesis of HAP, the adsorption of Gly, Ser and Asp on HAP crystal surface could change the crystalline size and the morphology of HAP, and could significantly increase the solubility of $\mathrm{HAP}^{[22]}$.

The present study verified the remineralization effect of HAP composites which were modified with different combinations of amino acids, and found that the AA/HAP synthesized in the presence of $10 \mathrm{mmol} / \mathrm{L}$ Gly, $10 \mathrm{mmol} / \mathrm{L}$ Ser and $5 \mathrm{mmol} / \mathrm{L}$ Asp showed optimal remineralization effect for both surface and subsurface lesions of acidetched bovine enamel. Since these three kinds of amino acids all have smaller molecular size and contain different side functional groups, they may act synergistically in the synthesis of AA/HAP and the remineralization of subsurface enamel lesions.

\section{Materials and methods}

\subsection{Materials}

Analytical grade $\mathrm{NaN}_{3}$ was purchased from Fuchen (Tianjin) Chemical Reagent Co, Ltd. Phosphate-Buffered
Saline (PBS) was purchased from Corning Mediatech, Inc. The 293T cells were purchased from Kunming Institute of Zoology, Chinese Academy of Sciences. All of the other reagents and solvents if not specified were purchased from Sinopharm Chemical Reagent Co, Ltd and were all analytical grade. Deionized (DI) water was used in all procedures.

\subsection{Synthesis of AA/HAP composite}

AA/HAP composite was synthesized using a chemical homogeneous precipitation method. $\mathrm{Ca}\left(\mathrm{NO}_{3}\right)_{2} \cdot 4 \mathrm{H}_{2} \mathrm{O}$ (14.169 g, $60 \mathrm{mmol})$, Gly $(2.580 \mathrm{~g}, 10 \mathrm{mmol} / \mathrm{L})$, Ser (3.573 g, $10 \mathrm{mmol} / \mathrm{L})$, and Asp (2.287 g, $5 \mathrm{mmol} / \mathrm{L})$ were dissolved in $1600 \mathrm{~mL}$ DI water, respectively. The mixture was heated and maintained at $(37 \pm 1){ }^{\circ} \mathrm{C}$ in the subsequent processes. $\left(\mathrm{NH}_{4}\right)_{2} \mathrm{HPO}_{4}(4.752 \mathrm{~g}, 35.98 \mathrm{mmol})$ dissolved in $800 \mathrm{~mL}$ DI water was slowly titrated into the prepared mixture in about $120 \mathrm{~min}$. $2.5 \mathrm{wt} \%$ ammonia solution was adopted to maintain $\mathrm{pH}$ of the mixture at $(10 \pm 0.5)$ during the titration process. After continuous stirring for $24 \mathrm{~h}$, the suspension aged at standing state for $24 \mathrm{~h}$ and washed with DI water until the $\mathrm{pH}$ decreased to about 7.0 to remove the impurities. The AA/HAP powder was obtained following the lyophilized of the precipitate for $12 \mathrm{~h}$. The HAP powder without amino acids was synthesized according to the above procedures.

\subsection{Cytotoxicity assay}

CCK-8 assay was performed to evaluate the cytotoxicity of the HAP and AA/HAP. The 3rd generation of 293T cells (one typical human renal epithelial cells transfected with adenovirus E1A gene) were cultured in $10 \%$ FBS at $37{ }^{\circ} \mathrm{C}$ (under an atmosphere of $5 \% \mathrm{CO}_{2}$ and $95 \%$ relative humidity). The cells were seeded in a 96-well culture plate at a density of $5.0 \times 10^{4}$ cells/well and incubated in $100 \mu \mathrm{L} \mathrm{FBS} /$ well for $24 \mathrm{~h}$. Then the culture medium was replaced by $100 \mu \mathrm{L}$ fresh FBS which containing a series dilutions of the HAP and the AA/HAP. The concentrations of the HAP and the AA/ HAP range from $0.05 \mathrm{~g} / \mathrm{mL}$ to $0.4 \mathrm{~g} / \mathrm{mL}$, respectively. After another $48 \mathrm{~h}$ incubation, $10 \mu \mathrm{L}$ CCK-8 solution was slowly added into each well, and the culture plate was incubated for $4 \mathrm{~h}$. Then the 96-well culture plate was placed on a microplate reader and the optical density (OD) in each well was measured at a wavelength of $450 \mathrm{~nm}$. The relative cell viability $(\% R C V)$ of the cells was calculated through the formula:

$$
\% R C V=\frac{O D_{t}-O D_{0}}{O D_{n}-O D_{0}} \times 100
$$

Where $O D_{t}, O D_{n}$ and $O D_{0}$ are the average optical density values of the wells contain experimental materials, the wells without experimental materials (negative control) and the wells without cells (blank control) respectively. 
For each concentration of the materials, the OD value of eight wells was measured, and the mean value \pm standard deviation was used.

\subsection{Preparation of enamel samples and enamel lesions}

Sound bovine molars of 2-3 years old cattle were selected in this investigation. After removal of the root and organic contaminants, the molars were cut into $3 \mathrm{~mm} \times$ $4 \mathrm{~mm} \times 2 \mathrm{~mm}$ enamel blocks using sintered diamond saw on a low-speed precision cutting machine. Then the enamel blocks were embedded in PMMA resin with the enamel lip exposed. The enamel surface was polished with water-cooled $\mathrm{SiC}$ sandpaper until a mirror-like surface was obtained, and no obvious scratches were observed under a stereomicroscope. The enamel samples were stored in PBS at $4{ }^{\circ} \mathrm{C}$.

The enamel samples were immersed in $3 \mathrm{wt} \%$ carboxymethyl cellulose gel $(\mathrm{pH}=4.0)$ which contains lactic acid $(0.1 \mathrm{~mol} / \mathrm{L})$ for $24 \mathrm{~h}$ to produce acid-etched lesions (the ratio of enamel surface area to solution volume was $2 \mathrm{~mm}^{2} / \mathrm{mL}$ ). After demineralization, the samples were washed with DI water and sonicated for $1 \mathrm{~min}$.

\subsection{Remineralization of the enamel in artificial saliva}

In order to simulate an oral environment, artificial saliva was prepared by dissolving $1.5 \mathrm{mmol} / \mathrm{L} \mathrm{CaCl}_{2}, 0.9 \mathrm{mmol} / \mathrm{L}$ $\mathrm{KH}_{2} \mathrm{PO}_{4}, 130 \mathrm{mmol} / \mathrm{L} \mathrm{KCl}$ and $20 \mathrm{mmol} / \mathrm{L} \mathrm{HEPES}$ in DI water ( $\mathrm{pH}$ was adjusted to 7.0 with $0.1 \mathrm{~mol} / \mathrm{L} \mathrm{KOH}$ ). $1.0 \mathrm{mmol} / \mathrm{L} \mathrm{NaN}_{3}$ was added to prevent bacterial growth.

The acid-etched enamel samples were soaked in $60 \mathrm{~mL}$ artificial saliva which contained $2.16 \mathrm{~g}$ HAP or AA/HAP (the ratio of HAP or AA/HAP to enamel surface is $0.03 \mathrm{~g} / \mathrm{mm}^{2}$ ). Then they were placed on a constant temperature shaker $\left(37^{\circ} \mathrm{C}\right)$ for $12 \mathrm{~h}$. After that, the samples were rinsed with DI water for $20 \mathrm{~s}$ and soaked in $60 \mathrm{~mL}$ artificial saliva at $37{ }^{\circ} \mathrm{C}$ for another $12 \mathrm{~h}$. A total of $21 \mathrm{~d}$ were performed in this cycle and the HAP or AA/ HAP suspension was replaced every $7 \mathrm{~d}$. Blank group: the enamel samples were soaked in artificial saliva at $37{ }^{\circ} \mathrm{C}$ for $21 \mathrm{~d}$ (artificial saliva was replaced every $12 \mathrm{~h}$ ).

\subsection{Mechanical property of the enamel samples}

The SMH values of the enamel samples were measured by a Vickers microhardness tester (THV-30MD, Lab Testing Technology (Shanghai) Co., Ltd.) under a $9.8 \mathrm{~N}$ load for $15 \mathrm{~s}$. The mean values of three points for each sample were recorded at different time (before demineralization, after demineralization, and after remineralization). Before the remineralization, the acid-etched enamel samples were arranged from large to small in order of the SMR values, and the samples were divided into three groups according to the principle of balanced distribution of the SMR values $(n=6)$. The degree of microhardness increase rate $(\% M H R)$ after remineralization was calculated through the formula:

$$
\% M H R=\frac{M H_{2}-M H_{1}}{M H_{1}} \times 100
$$

where $M H_{1}$ is the mean value of microhardness after demineralization, $\mathrm{MH}_{2}$ is the mean value of microhardness after remineralization.

\subsection{Characterization}

Fourier transform infrared spectroscopy (FT-IR) of the HAP and the AA/HAP were recorded on an FT-IR spectrometer (EQUINOX-55, Germany). Structure and crystallinity analysis were performed on X-ray diffractometer (PANalytical Empyrean, $40 \mathrm{kV}, 40 \mathrm{~mA}$, Netherlands). Crystalline size, morphology and interfacial bonding of the HAP and the AA/HAP were characterized by transmission electron microscope (TEM) (JEOL JEM-2100, Japan). High resolution transmission electron microscope (HRTEM) and fast Fourier transform (FTT) results were obtained using the TEM device. The $\mathrm{Ca}^{2+}$ concentration in the supernatant of the remineralization solution containing HAP and AA/HAP was measured by inductively coupled plasma-optical emission spectrometry (ICP-OES, USA).

The surface and cross-section morphology of the enamel samples were observed by field emission scanning electron microscope (FESEM) (FEI Nova NanoSEM 450, Netherlands). The samples were sputtered with $\mathrm{Au}$ for $250 \mathrm{~s}$ before the FESEM characterization. The full area $\mathrm{Ca} / \mathrm{P}$ molar ratio of the enamel surface was obtained from energy dispersive X-ray spectroscopy (EDX, Oxford Instrument $\mathrm{Co}, \mathrm{UK}$.). The crystal type and crystallinity of the enamel surface was performed on X-ray diffractometer (PANalytical Empyrean, $40 \mathrm{kV}, 40 \mathrm{~mA}$, Netherlands).

\subsection{Statistical analysis}

The $\% R C V$ of the HAP and the AA/HAP composite were expressed as mean \pm standard deviation. The $\mathrm{SMH}$ data of enamel samples were also expressed as mean \pm standard deviation. One-way ANOVA was applied for overall comparison of the SMH values after demineralization. The comparisons between the SMH value before and after remineralization for each experimental group were analyzed by paired sample $t$-test. The value of $p<$ 0.05 is considered significant.

\section{Results and discussion}

\subsection{Characterization of the HAP and AA/HAP composite}

Fig. 1 shows the FT-IR spectra of the HAP and 
AA/HAP composite. The bands at 1095/1037/962 and $603 / 565 \mathrm{~cm}^{-1}$ are ascribed to the stretching vibration and the bending vibration of $\mathrm{PO}_{4}{ }^{3-}$, respectively. The bands at 3450 and $1635 \mathrm{~cm}^{-1}$ are assigned to the stretching vibrations of $-\mathrm{OH}$ and the bending mode of adsorbed water. These characteristic bands prove that both of the materials are HAP. The vibration bands of $\mathrm{N}-\mathrm{H}$ and $\mathrm{C}=\mathrm{O}$ are included in $3450 / 1635$ and $1635 \mathrm{~cm}^{-1}$, respectively. The intensity of the AA/HAP at 1500-1400 and 1200-1000 $\mathrm{cm}^{-1}$ are strengthened by the symmetric/asymmetric stretches of $-\mathrm{COO} / \mathrm{NH}_{2} \cdots \mathrm{H}^{+[23]}$ and the stretching vibrations of $\mathrm{C}-\mathrm{O}$, respectively. These results prove the chemical bonding amino acids contained in AA/HAP.

Fig. 2 presents the XRD patterns of the HAP and AA/HAP. Both of the patterns show the characteristic peaks of HAP indexed as (002), (102), (112), (202), (310), (222), (213), (004) and (304) (JCPDS No.090432). The diffraction peaks of both materials at $2 \theta$ of $30^{\circ}-34^{\circ}$ are significantly broadened, indicating the small crystalline size of the synthesized nanoparticles. Meanwhile, AA/HAP diffraction peaks are lower and broader than HAP. It can be concluded that the AA/HAP has lower crystallinity ${ }^{[23]}$. The passivated and weak peaks of (002) and (004) planes are attributed to the inhibition effect of the complex amino acids on the crystal growth of $c$-axis.

The $\alpha$-carboxyl and hydroxyl group of Ser could tightly adsorb on (002) and (004) lattice planes of HAP,

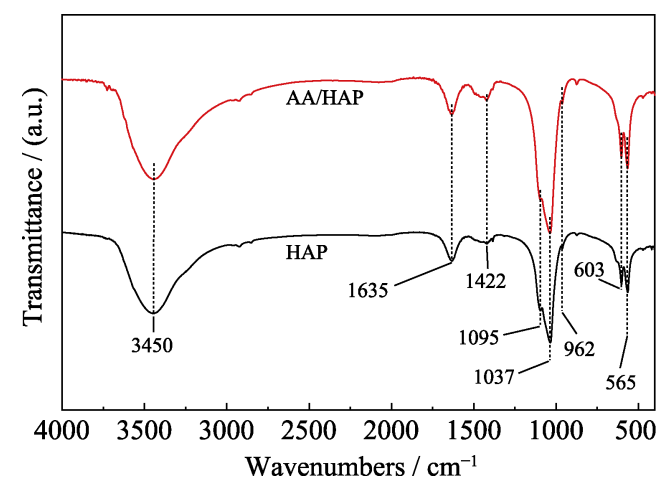

Fig. 1 FT-IR spectra of the HAP and AA/HAP composite

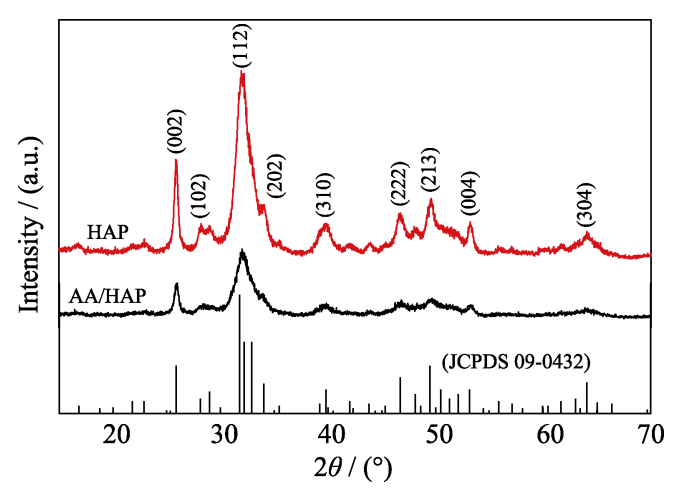

Fig. 2 XRD patterns of the HAP and AA/HAP composite thus the crystal growth perpendicular to $c$-axis was inhibited $^{[22-23]}$. The acidic amino acid Asp has a high affinity on the HAP crystal faces parallel to the $c$-axis ${ }^{[24-25]}$. With both side terminal carboxyl groups binding to crystal planes, the preferred crystal growth perpendicular to the (310) plane was reduced significantly. The size of a Gly molecule is about $0.3 \mathrm{~nm}^{[26]}$, while the internal channels in the crystal lattice of HAP which are occupied by $\mathrm{OH}$ groups are $0.3-0.35 \mathrm{~nm}$ in diameter ${ }^{[27]}$. Therefore, Gly molecules could enter these channels and simultaneously interact with the crystal lattice around these channels, eventually changed the crystallinity of HAP. It can be concluded that the AA/HAP composite with lower crystallinity would help to increase its solubility in the remineralization.

Fig. 3 reveals the TEM images of the HAP and AA/HAP. The typical TEM image of the HAP (Fig. 3(a1)) shows an enamel prism-like morphology with a length of $50-150 \mathrm{~nm}$ and a diameter of 8-12 $\mathrm{nm}$. The interplanar spacing distances of $d=0.339 \mathrm{~nm}$ (Fig. 3(a2)) are corresponding to the (002) faces of the HAP. This result is consistent with the preferred growth of (002) face shown in the XRD pattern (Fig. 2), and demonstrates that the [001] is the preferred crystallizing direction. The diffraction spots in the FTT image are due to (002) (the brighter spots) and (211) (the darker spots) faces of the HAP, respectively. The TEM image of the AA/HAP (Fig. 3(b1)) shows a prism-like morphology with a length of approximately $100 \mathrm{~nm}$ and a diameter of 3-6 nm. This result proves again the inhibition effect of amino acids on the crystal growth along $a$ and $b$-axis. The diffraction
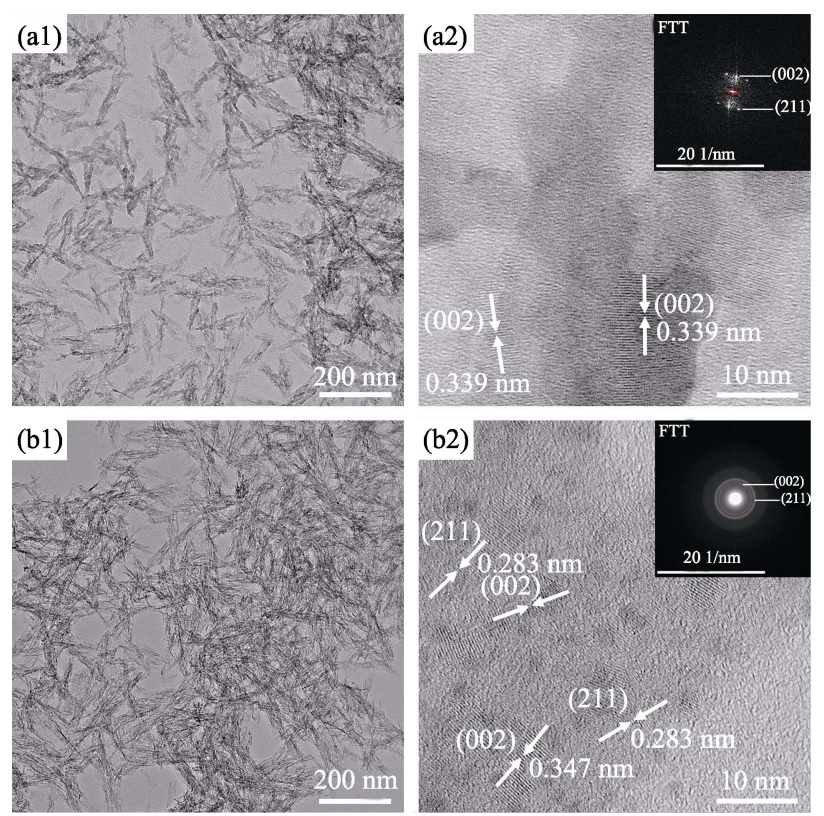

Fig. 3 TEM images of the HAP (a1) and AA/HAP (b1); HRTEM of the HAP (a2) and AA/HAP (b2) with inserts showing their corresponding FTT images 
circles shown in the FTT image of AA/HAP (insert in Fig. 3(b2)) are corresponding to the (002) and (211) faces of AA/HAP, respectively, indicating that the nanoparticles are randomly oriented. The HRTEM image of the AA/ HAP proves again that the crystalline of the nanoparticles are significant refinement. The interplanar spacing distances of $d=0.347$ and $0.283 \mathrm{~nm}$ are ascribed to the (002) and (211) faces of AA/HAP, respectively. The black spots with a diameter of $2.5-3.5 \mathrm{~nm}$ (in the background of Fig. 3(b2)) may be attributed to the carbonization of the amino acids trapped in the crystals of AA/HAP. Both of the XRD and the TEM results illustrate that the AA/HAP has smaller crystalline size and lower crystallinity. These properties could increase the solubility of the AA/HAP in artificial saliva, and may be favorable for the release of $\mathrm{Ca}^{2+}$ and $\mathrm{PO}_{4}{ }^{3-}$ ions during the remineralization.

The cytotoxicity of the HAP and AA/HAP composite at various concentrations range from $0.05 \mathrm{~g} / \mathrm{mL}$ to $0.4 \mathrm{~g} / \mathrm{mL}$ was evaluated by CCK-8 assay. As shown in Fig. 4, both of the materials present no cytotoxicity within a wide range of concentrations. Nevertheless, $\% R C V$ of HAP is far lower than that of AA/HAP. Thus the AA/HAP composite presents better biocompatibility than the HAP.

Fig. 5 shows the $\mathrm{Ca}^{2+}$ concentration in the supernatant of remineralization solution containing HAP and AA/HAP.

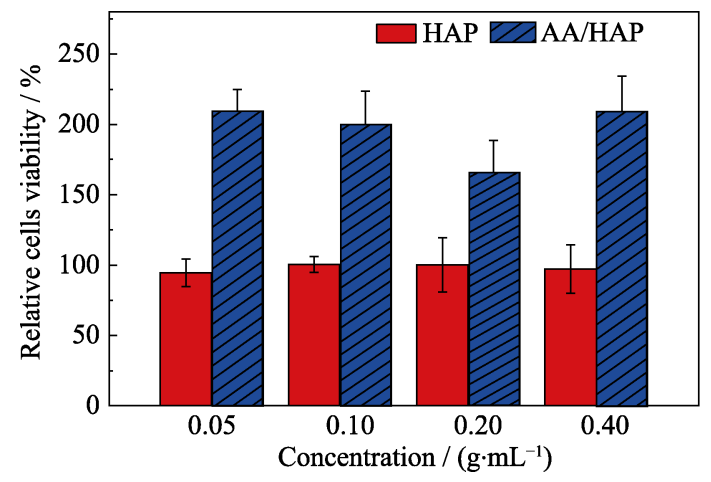

Fig. 4 CCK- 8 assay of the HAP and AA/HAP at different concentrations

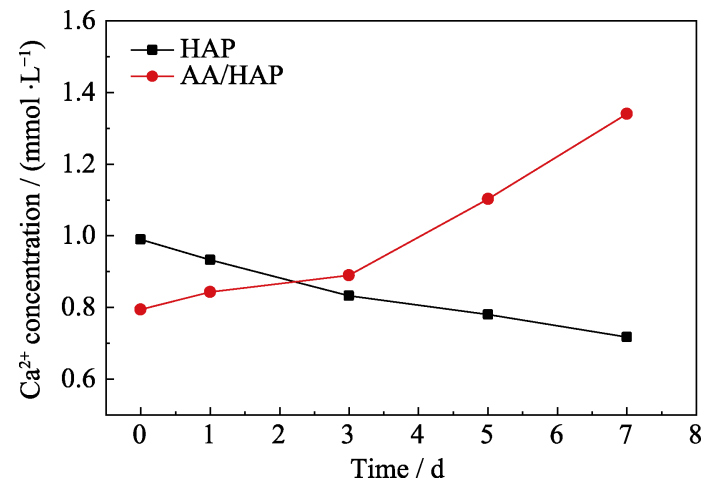

Fig. $5 \mathrm{Ca}^{2+}$ concentration in the supernatant of remineralization solution
Once the HAP and AA/HAP were added into artificial saliva, the $\mathrm{Ca}^{2+}$ concentrations were both lower than that of artificial saliva $(1.5 \mathrm{mmol} / \mathrm{L})$. This result may be attributed to the chelating effect of both materials on $\mathrm{Ca}^{2+}$, which reduces the $\mathrm{Ca}^{2+}$ concentration of the remineralization solution in a short time. At the same time, the initial value of AA/HAP is lower than that of HAP, which may be due to its higher specific surface area. The $\mathrm{Ca}^{2+}$ concentration of the HAP-containing solution gradually decreased to about $0.72 \mathrm{mmol} / \mathrm{L}$ in $7 \mathrm{~d}$, while the AA/HAP-containing solution gradually increased to approximately $1.34 \mathrm{mmol} / \mathrm{L}$. This result proves the higher solubility of AA/HAP than HAP.

\subsection{In vitro remineralization of acid-etched bovine enamel}

After the remineralization, the surface and cross-section morphology of the enamel were measured by FESEM. The EDX, XRD and Vickers microhardness of the enamel surface were characterized, respectively.

\subsubsection{Characterization of the surface and cross- section morphology}

Fig. 6 presents the surface and cross-section FESEM images of the sound enamel and acid-etched enamel. The sound enamel has a dense surface without obvious gaps (Fig. 6(a1)). Its cross-section is also intact (Fig. 6 (a2)). The acid-etched enamel has a scaly-like surface with large gaps between the enamel rods (Fig. 6(b1)), and the enamel prisms can be clearly seen. The cross-section image of the acid-etched enamel (Fig. 6(b2)) presents severe subsurface lesions with a depth up to $30 \mu \mathrm{m}$. In the primary hierarchical structure, enamel consists of enamel rod, rod sheath and inter-rod mineral ${ }^{[4]}$. These rod sheaths are hydrophobic and can protect the enamel rods from acid erosion ${ }^{[1]}$. The inter-rod mineral has lower crystallinity, and contains a small amount of organic
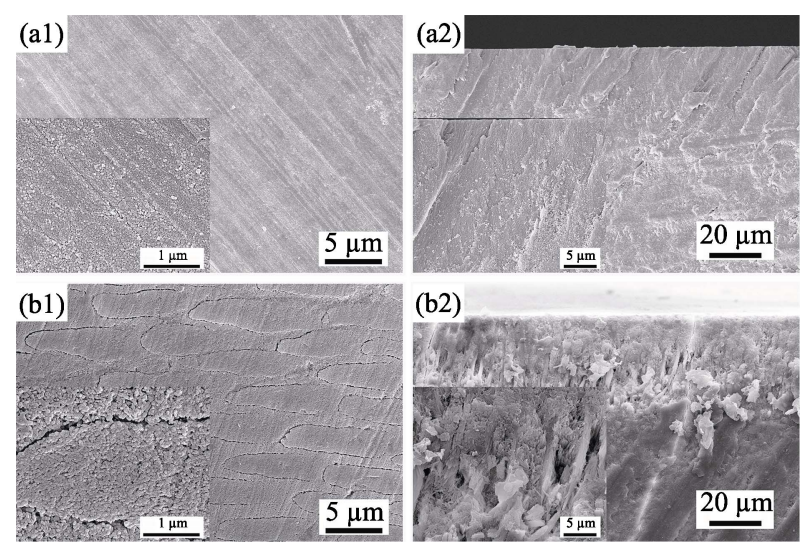

Fig. 6 Surface and cross-section FESEM images of the enamel: sound enamel (a1) and (a2), acid-etched enamel (b1) and (b2) with insert in each image showing corresponding enlarged view 
remnants. Meanwhile, the subsurface enamel prisms contain higher metal ions such as $\mathrm{K}^{+}, \mathrm{Na}^{+}$and $\mathrm{Mg}^{2+}$ than the surface prisms ${ }^{[28]}$. The potassium, sodium and magnesium phosphates are more vulnerable to acid etching, eventually leading to more serious subsurface lesions.

Fig. 7 shows the FESEM images of the enamel surface and cross-section after remineralization. The blank group also formed a mineral layer on its surface (Fig. 7(a1)). This may attribute to the self-repair ability of the acid-etched enamel in artificial saliva ${ }^{[9]}$. Despite the relatively intact surface, the blank group still presents obvious defects beneath the surface area. Both of the limited $\mathrm{Ca}^{2+}$ ions in artificial saliva and the restricted $\mathrm{Ca}^{2+}$ bioavailability of the acid-etched enamel restrained the subsurface remineralization ${ }^{[29]}$. The surface image of the HAP treated group (Fig. 7(b1)) shows many inter-rod gaps. And only a small amount of minerals adsorb on the surface. This result means that the HAP is mainly utilizing the adsorption properties to fill the cavities of the enamel surface ${ }^{[8,17]}$. The cross-section image of the HAP group (Fig. 7(b2)) shows a similar defect to the blank group, but presents deeper unrepaired subsurface lesions. As mentioned above, the crystallinity of the HAP is relatively high, resulting in lower solubility and limited $\mathrm{Ca}^{2+}$ and $\mathrm{PO}_{4}{ }^{3-}$ ions concentration in the remineralization. As shown in Fig. 5, the HAP particles may adsorb $\mathrm{Ca}^{2+}$ and $\mathrm{PO}_{4}{ }^{3-}$ ions, and re-grow in artificial saliva, therefore, leading to a worse repair effect than the blank group.

The AA/HAP treated group obtained the densest mineral layer on the enamel surface (Fig. 7(c1). The insert
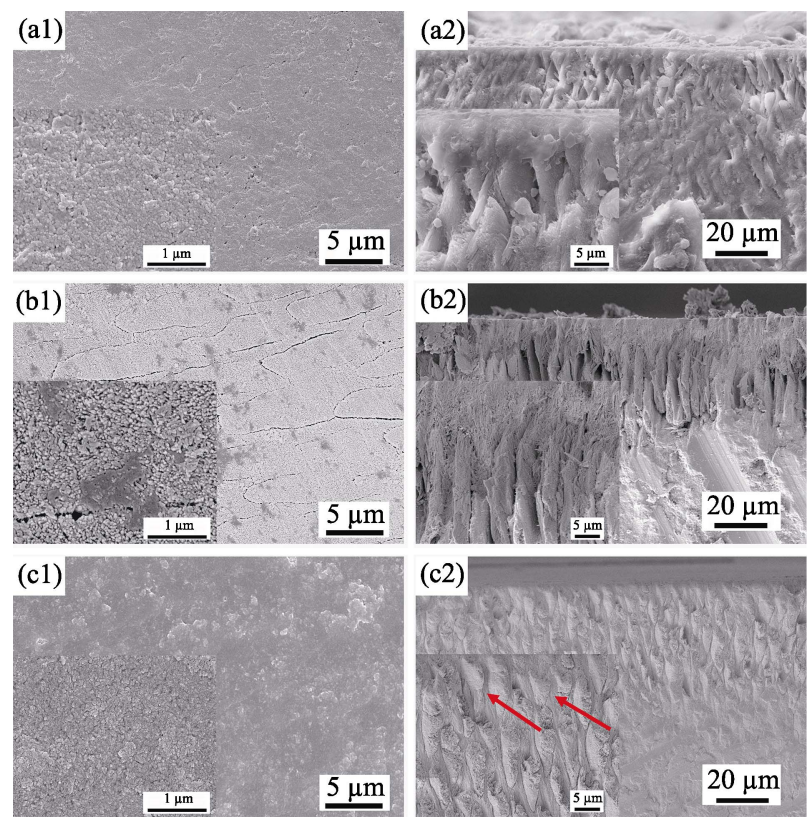

Fig. 7 Surface and cross-section FESEM images of the enamel: blank group (a1, a2), HAP (b1, b2), and AA/HAP (c1, c2) with insert in each image showing corresponding to its enlarged view image proves the existence of newly formed nanoparticles. The AA/HAP synthesized in the presence of Gly, Ser and Asp shows poor crystallinity and higher solubility ${ }^{[22]}$. Therefore, more $\mathrm{Ca}^{2+}$ and $\mathrm{PO}_{4}{ }^{3-}$ ions could be provided for surface remineralization of the enamel samples, just as shown in Fig. 5. Meanwhile, the molecules of amino acids could adsorb on the enamel surface and attract $\mathrm{Ca}^{2+}$ and $\mathrm{PO}_{4}{ }^{3-}$ ions to sustain the topical supersaturation ${ }^{[30]}$, ultimately promote the HAP crystal growth. The cross-section image of the AA/HAP group (Fig. 7(c2)) shows an intact morphology with no defect exists. Furthermore, parallel arranged crystals formed in the inter-rod area (red arrows in Fig. 7(c2)). The molecular size of amino acids is very small compared with macromolecular components (such as polypeptides and amelogenin). This feature facilitates the rapid diffusion of amino acids molecules from remineralization solution to deep lesions. Then the amino acids could adsorb on the organic matrix residues and promote the orderly growth of HAP crystals. In summary, if dissolved in solution, amino acids would inhibit the crystal growth of HAP by chelating $\mathrm{Ca}^{2+}$ and $\mathrm{PO}_{4}{ }^{3-}$ ions or binding to the nuclei of calcium phosphate. When adsorbed on organic residues, the side functional groups (such as carboxyl and hydroxyl) of amino acids would become nucleation sites. These nucleation sites would regulate the crystal growth of HAP along parallel orientation ${ }^{[20,30]}$.

\subsubsection{Components analysis}

Table 1 reveals the elemental composition results of the enamel surface. The $\mathrm{Ca} / \mathrm{P}$ molar ratio of sound enamel surface is 1.62 , which is lower than that of empirically derived HAP $(\mathrm{Ca} / \mathrm{P}=1.67)$. This result indicates that enamel is composed of calcium-deficient HAP. Calcium ions in the phosphorus-oxygen tetrahedron in apatite are more susceptible to acid corrosion than phosphate ions. Therefore, the $\mathrm{Ca} / \mathrm{P}$ molar ratio of the acid-etched enamel decreased significantly to 1.48 . After the remineralization, the $\mathrm{Ca} / \mathrm{P}$ molar ratio of the blank group, HAP group and AA/HAP group increased to 1.58, 1.63 and 1.65, respectively. The $\mathrm{Ca} / \mathrm{P}$ molar ratio of the $\mathrm{AA} / \mathrm{HAP}$ group is higher than that of sound enamel, and is very close to 1.67 , indicating that the surface of the acid-etched enamel is well repaired. Meanwhile, the higher component of $\mathrm{O}$

Table 1 Ca/P molar ratio of the enamel surface

\begin{tabular}{ccccc}
\hline \multirow{2}{*}{ Sample } & \multicolumn{3}{c}{ Elemental composition $/ \mathrm{at} \%$} & \multirow{2}{*}{$\begin{array}{c}\mathrm{Ca} / \mathrm{P} \\
\text { ratio }\end{array}$} \\
\cline { 2 - 4 } & $\mathrm{O}$ & $\mathrm{P}$ & $\mathrm{Ca}$ & \\
\hline Polished enamel & 19.86 & 17.97 & 29.04 & 1.62 \\
Acid-etched enamel & 25.95 & 19.34 & 28.59 & 1.48 \\
Blank group & 14.07 & 17.59 & 27.85 & 1.58 \\
HAP group & 19.63 & 16.05 & 26.20 & 1.63 \\
AA/HAP group & 40.61 & 17.87 & 29.49 & 1.65 \\
\hline
\end{tabular}


in the AA/HAP treated group may attribute to the carboxyl and side functional groups of amino acids.

The XRD patterns of the enamel surface are shown in Fig. 8. All of the patterns show the characteristic peaks of HAP indexed as (002), (211), (112), (202), (222), (213), (004) and (304). The diffraction peak of (310) lattice plane at $2 \theta=39.82^{\circ}$ almost disappears, indicating that the crystals locating in the enamel surface have tiny crystalline size along the crystallographic $a$-axis. The sharp and intense (002) and (004) lattice planes of the sound enamel (Fig. 8(a)) illustrate that the enamel surface is comprised of parallel arranged crystals in the orientation of $c$-axis direction ${ }^{[31]}$. The enamel prisms in the surface and subsurface area are severely corroded, thus the peak intensities of the acid-etched enamel (Fig. 8(b)) decrease greatly. Meanwhile, its XRD pattern shows a broadened and weakened peak at $2 \theta=32-35^{\circ}$. These results demonstrate that the surface prisms of the acid-etched enamel have lost crystal lattice ${ }^{[32]}$. After remineralization, the peak intensities of (002) and (004) faces strengthen in all the three experimental groups. This result proves the restoration of the enamel prisms along $c$-axis direction. For the characteristic peaks at $2 \theta=31^{\circ}-33^{\circ}$, the AA/HAP group (Fig. 8(e)) shows lower intensity and broadened pattern. This result is consistent with the FESEM image shown in Fig. 7(c1). It proves the abundant regenerated nanoparticles formed on the enamel surface.

\subsubsection{Mechanical property}

The mechanical property of the enamel represents changes in microstructure. Fig. 9 shows that the SMH values of all the enamel samples decreased significantly after acid-etch. One-way ANOVA shows that there is no significant difference in SMH among the experimental groups after demineralization $(p>0.05)$. The SMH of the blank group before and after remineralization are almost identical. Paired sample $t$-test analysis shows that there are significant difference between the SMH before and

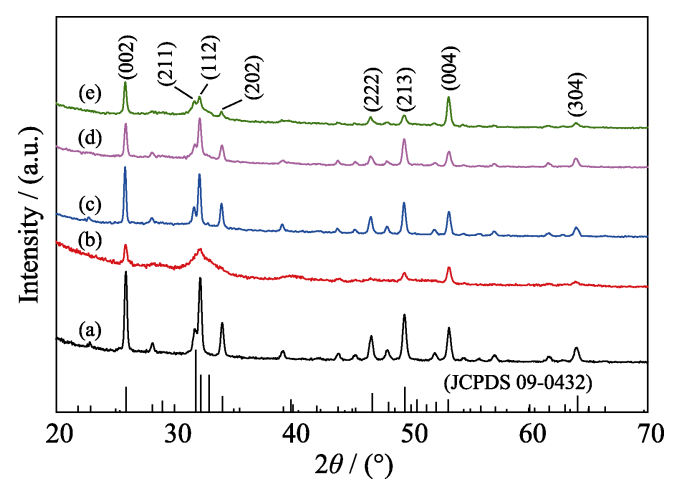

Fig. 8 XRD patterns of the enamel surface: sound enamel (a); acid-etched enamel (b); blank group (c); HAP group (d) and AA/HAP group (e)

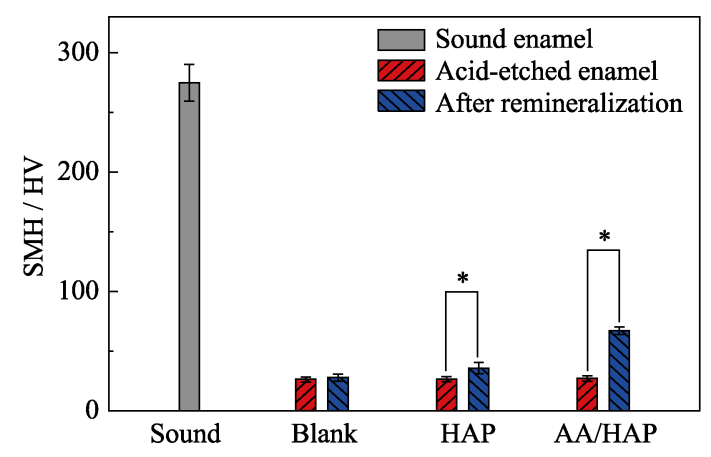

Fig. 9 Comparison of the SMH before demineralization, after demineralization and after remineralization

after remineralization both for the HAP group and the AA/HAP group $(p<0.05)$. Nonetheless, the SMH of the HAP treated group is still lower than that of the AA/HAP group, which could also be verified by the poor subsurface remineralization in the cross-section morphology (Fig. 7(b2)). In summary, the $\% M H R$ of the blank group, HAP group and AA/HAP group are 5.52\%, 35.07\% and $148.42 \%$, respectively. However, compared with the SMH of sound enamel, the SMH of AA/HAP group is still very low. Enamel has a complex hierarchical structure reinforced by the precise arrangement of rods and the organic remnants $^{[4]}$. Once eroded into the inner area, this delicate structure would be destroyed and the complete recovery of the SMH could not be realized ${ }^{[33]}$.

\section{Conclusions}

In this study, amino acids/hydroxyapatite (AA/HAP) composite was synthesized to evaluate its remineralization effect on acid-etched bovine enamel. Compared with the HAP without amino acids, the AA/HAP composite with refined crystalline size and lower crystallinity was obtained under the inhibition effect of Gly, Ser and Asp. Cytotoxicity assay proved better biocompatibility of the AA/HAP composite than the HAP. In artificial saliva, AA/HAP could sustain a calcium supersaturation circumstance and induce restoration of both surface and subsurface lesions in acid-etched bovine enamel. The molecular size of Gly, Ser and Asp are all very small, thus facilitate the rapid diffusion of these molecules into deep lesions and the adsorption on organic matrix residues. The parallel arranged HAP crystals which are beneficial for the recovery of SMH may be promoted by these adsorbed amino acids. The current approach may provide a safe, economical and effective strategy for the treatment of early enamel lesions.

\section{References:}

[1] DUVERGER O, BENIASH E, MORASSO M I. Keratins as components of the enamel organic matrix. Matrix Biology, 2016, 
ponents of the enamel organic matrix. Matrix Biology, 2016, 52/54: $260-265$.

[2] CAO Y, MEI L, LI Q L, et al. Methods for biomimetic mineralisation of human enamel: a systematic review. Materials, 2015, 8(6): 2873-2886.

[3] YEOM B, SAIN T, LACEVIC N, et al. A biotic tooth enamel. $\mathrm{Na}$ ture, 2017, 543(7643): 95-98.

[4] HE L H, SWAIN M V. Understanding the mechanical behavior of human enamel from its structural and compositional characteristics. Journal of the Mechanical Behavior of Biomedical Materials, 2008, 1(1): 18-29.

[5] WEINER S, ADDADI L. Design strategies in mineralized biological materials. Journal of Materials Chemistry, 1997, 7(5): 689-702.

[6] ENSANYA A N, ANAS A, ADAM S, et al. Demineralizationremineralization dynamics in teeth and bone. International Journal of Nanomedicine, 2016, 11: 4743-4763.

[7] FEATHERSTONE J D B, LUSSI A. Understanding the chemistry of dental erosion. Monographs in Oral Science, 2006, 20: 66-76.

[8] LI X, WANG J, JOINER A, et al. The remineralisation of enamel: a review of the literature. Journal of Dentistry, 2014, 42(S1): S12-S20.

[9] CHEN M, YANG J, LI J, et al. Modulated regeneration of acid-etched human tooth enamel by a functionalized dendrimer that is an analog of amelogenin. Acta Biomaterialia, 2014, 10(10): 4437-4446.

[10] RUAN Q, ZHANG Y, YANG X, et al. Amelogenin-chitosan matrix promotes assembly of an enamel-like layer with a dense interface. Acta Biomaterialia, 2013, 9(7): 7289-7297.

[11] GUNGORMUS M, OREN E, HORST J A, et al. Cementomimeticsconstructing a cementum-like biomineralized microlayer via amelogeninderived peptides. International Journal of Oral Science, 2012, 4(2): 69-77.

[12] CHUNG H Y, LI C, HSU C. Characterization of the effects of 3DSS peptide on remineralized enamel in artificial saliva. Journal of the Mechanical Behavior of Biomedical Materials, 2012, 6: 74-79.

[13] LOW I M. Depth-profiling of crystal structure, texture, and microhardness in a functionally graded tooth enamel. Journal of the American Ceramic Society, 2004, 87(11): 2125-2131.

[14] AL-OBAIDI R, SALEHI H, DESOUTTER A, et al. Chemical \& nano-mechanical study of artificial human enamel subsurface lesions. Scientific Reports, 2018, 8(1): 4047.

[15] BERGSTRAND F, TWETMAN S. A review on prevention and treatment of post-orthodontic white spot lesions-evidence-based methods and emerging technologies. The Open Dentistry Journal, 2011, 5(1): 158-162.

[16] ROVERI N, BATTISTELla E, FOLTRAN I, et al. Synthetic biomimetic carbonate-hydroxyapatite nanocrystals for enamel remineralization. Advanced Materials Research, 2008, 47-50: 821-824.

[17] LI L, PAN H, TAO J, et al. Repair of enamel by using hydroxyapatite nanoparticles as the building blocks. Journal of Materials Chemistry, 2008, 18: 4079-4084.

[18] ROBINSON C, LOWE N R, WEATHERELL J A. Amino-acid composition, distribution and origin of "tuft" protein in human and bovine dental enamel. Archives of Oral Biology, 1975, 20(1):
29-42.

[19] PAN H, TAO J, XU X, et al. Adsorption processes of Gly and Glu amino acids on hydroxyapatite surfaces at the atomic level. Langmuir, 2007, 23(17): 8972-8981.

[20] TAVAFOGHI M, CERRUTI M. The role of amino acids in hydroxyapatite mineralization. Journal of the Royal Society Interface, 2016, 13(123): 1-12.

[21] FAN Z J, WANG J Q, WANG Z F, et al. One-pot synthesis of graphene/ hydroxyapatite nanorod composite for tissue engineering. Carbon, 2014, 66(1): 407-416.

[22] MATSUMOTO T, OKAZAKI M, INOUE M, et al. Crystallinity and solubility characteristics of hydroxyapatite adsorbed amino acid. Biomaterials, 2002, 23(10): 2241-2247.

[23] GONZALEZ-MCQUIRE R, CHANE-CHING J Y, VIGNAUD E, et al. Synthesis and characterization of amino acid-functionalized hydroxyapatite nanorods. Journal of Materials Chemistry, 2004, 14(14): 2277-2281.

[24] LI L, MAO C, WANG J, et al. Bio-inspired enamel repair via Glu-directed assembly of apatite nanoparticles: an approach to biomaterials with optimal characteristics. Advanced Materials, 2011, 23(40): 4695-4701.

[25] BOANINI E, TORRICELLI P, GAZZANO M, et al. Nanocomposites of hydroxyapatite with aspartic acid and glutamic acid and their interaction with osteoblast-like cells. Biomaterials, 2006, 27(25): 4428-4433.

[26] MORO D, ULIAN G, VALDRÈ G. Single molecule investigation of glycine-chlorite interaction by cross-correlated scanning probe microscopy and quantum mechanics simulations. Langmuir, 2015, 31(15): 4453-4463.

[27] KRUKOWSKI S, LYSENKO N, KOLODZIEJSKI W. Synthesis and characterization of nanocrystalline composites containing calcium hydroxyapatite and glycine. Journal of Solid State Chemistry, 2018, 264: 59-67.

[28] LAURANCE-YOUNG P, BOZEC L, GRACIA L, et al. A review of the structure of human and bovine dental hard tissues and their physicochemical behavior in relation to erosive challenge and remineralisation. Journal of Dentistry, 2011, 39(4): 266-272.

[29] CAI F, SHEN P, WALLKER G D, et al. Remineralization of enamel subsurface lesions by chewing gum with added calcium. Journal of Dentistry, 2009, 37(10): 763-768.

[30] MATSUMOTO T, OKAZAKI M, INOUE M, et al. Role of acidic amino acid for regulating hydroxyapatite crystal growth. Dental Materials Journal, 2006, 25(2): 360-364.

[31] FAN Y, SUN Z, MORADIANOLDAK J. Controlled remineralization of enamel in the presence of amelogenin and fluoride. Biomaterials, 2009, 30(4): 478-483.

[32] ZHANG X, LI Y, SUN X, et al. Biomimetic remineralization of demineralized enamel with nano-complexes of phosphorylated chitosan and amorphous calcium phosphate. Journal of Materials Science: Materials in Medicine, 2014, 25(12): 2619-2628.

[33] KOUlOURIDES T, CUETO H, PIGMAN W. Rehardening of softened enamel surfaces of human teeth by solutions of calcium phosphates. Nature, 1961, 189(4760): 226-227. 


\section{氨基酸/羟基磷灰石复合材料应用于酸蚀牛牙釉质体外再矿化}

刘继涛 ${ }^{1,2}$, 钢定泽 ${ }^{1}$, 杨泽斌 ${ }^{1}$, 陈希亮 ${ }^{1}$, 颜廷亭 ${ }^{1}$, 陈庆华 ${ }^{1}$

(1. 昆明理工大学 材料科学与工程学院, 昆明 650093 ; 2. 云南白药集团股份有限公司, 昆明 650500)

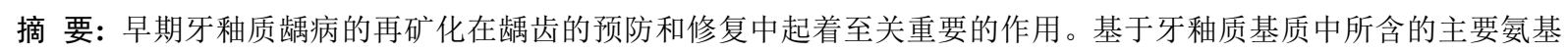
酸, 在 $10 \mathrm{mmol} / \mathrm{L}$ 甘氨酸、 $10 \mathrm{mmol} / \mathrm{L} \mathrm{L}$-丝氨酸和 $5 \mathrm{mmol} / \mathrm{L} \mathrm{L}$-天冬氨酸的存在下制备了氨基酸/着基磷灰石(AA/HAP) 复合材料, 表征了其物理、化学和生物学性质, 并评估了其对酸蚀牛牙釉质的再矿化作用。与不含氨基酸的羟基磷 灰石(HAP)相比, 在氨基酸的抑制作用下, AA/HAP 复合材料具有更低的结晶度和更高的生物相容性。在人工唾液 中用 $\mathrm{AA} / \mathrm{HAP}$ 对酸蚀牛牙釉质进行体外再矿化。再矿化后, 分别表征了牛牙釉质样品的表面和横截面形态、成分 和力学性能。结果表明, AA/HAP 可以诱导表面和深层牙釉质病变的修复。复合材料中释放的氨基酸可以吸附在有 机基质残基上并诱导平行排列的 HAP 晶体的形成, 从而使牙釉质表面显微硬度(SMH)得到显著恢复。最后, 讨论 了 $\mathrm{AA} / \mathrm{HAP}$ 复合材料对酸蚀牛牙釉质的再矿化机制。

关 键 词: 再矿化; 牙釉质; 羟基磷灰石; 氨基酸

中图分类号: R318 文献标识码: A 